\title{
The use of intravenous iron in pregnancy: for whom and when? A survey of Australian and New Zealand obstetricians
}

\author{
Sarah Smith-Wade ${ }^{1}$ (D) Giselle Kidson-Gerber ${ }^{1,2}$, Antonia Shand ${ }^{1,3,4}$, Luke Grzeskowiak ${ }^{5,6}$ and Amanda Henry ${ }^{1,7,8^{*}}$
}

\begin{abstract}
Background: Iron deficiency anaemia in pregnancy (IDAP) affects 11-18\% of Australian pregnancies and is associated with adverse perinatal outcomes. National prescribing data suggests the use of intravenous iron in pregnancy is increasingly common. This study aimed to: 1) Establish the current patterns of intravenous iron use by Fellows of the Royal Australian and New Zealand College of Obstetricians (FRANZCOG) when treating iron deficiency and IDAP including immediately postpartum and; 2) Assess FRANZCOG opinions regarding potential trial of intravenous iron for first-line treatment of IDAP.
\end{abstract}

Methods: An online survey of RANZCOG Fellows practicing obstetrics was distributed in September 2018. Results were analysed descriptively and responses compared by clinician demographics using Chi-squared testing.

Results: Of 484 respondents (21\% of FRANZCOG), 457 were currently practicing obstetrics. Most prescribed intravenous iron in pregnancy (96\%) and/or postpartum (85\%). Most intravenous iron was prescribed for IDAP (98\%) rather than iron deficiency without anaemia (53\%), and for IDAP most commonly second-line to failed oral iron supplementation and first-line in special circumstances (59\%). Intravenous iron prescribing was associated with shorter time since FRANZCOG completion $(p=0.01)$, public hospital practice $(p=0.008)$ and higher hospital birth numbers $(p=0.01)$. Most respondents $(90 \%)$ would consider a randomised controlled trial of first-line intravenous iron for IDAP, although views on appropriate thresholds differed.

Conclusions: Almost all respondents prescribed intravenous iron for IDAP, and while mostly used for second-line treatment over half sometimes used it first-line. With accelerating intravenous iron use, further research is required into its optimal use in pregnancy, recognizing important clinical outcomes and cost effectiveness.

\section{Background}

The prevalence of iron deficiency anaemia in pregnancy (IDAP) is estimated to be $20 \%$ globally [1] and $11-18 \%$ in Australia [2, 3]. All-cause severe anaemia is associated with increased maternal risks of blood transfusion, prolonged hospitalisation and maternal mortality [4, 5],

\footnotetext{
* Correspondence: amanda.henry@unsw.edu.au

'School of Women's and Children's Health, University of New South Wales, Kensington, NSW, Australia

7Department of Women's and Children's Health, Level 2, Prichard Wing, St George Hospital, Sydney, NSW, Australia

Full list of author information is available at the end of the article
}

alongside increased infant risks of perinatal death, small for gestational age and premature delivery [6, 7]. Given these associations the importance of treating IDAP is generally well accepted, despite limited quality data on the correlation between treatment and clinical outcomes [8].

The treatment of iron deficiency (ID) in pregnancy, with or without anaemia, has undergone significant shifts recently. This is multifactorial, including more screening and hence greater diagnosis of ID, the introduction of newer intravenous iron preparations [9] and increased recognition of the importance of patient blood management with new national guidelines [10]. Current 
Australian maternity guidelines recommend oral iron supplementation as first-line treatment for IDAP, as a 'Grade B' recommendation reflecting sufficient quality literature to guide practice in most situations. However, $10-40 \%$ of women taking oral iron experience significant gastrointestinal adverse effects, negatively impacting adherence [2]. Indeed, in a recent survey of Australian women, of those with oral iron adverse effects, 20\% ceased supplements before course completion (unpublished observations). For this reason, Australian guidelines have recently been updated to recommend either lower dose or intermittent dosing of oral iron supplementation to improve tolerability.

Australian antenatal care guideline recommend intravenous iron when there is poor response to or inability to comply with oral therapy [11]. Additionally, Australian patient blood management guidelines recommend intravenous iron first-line when "rapid restoration ... is required", such as when delivery is imminent [10].

Rates of intravenous iron use more than doubled in Australian women of reproductive age between 2014 and $2017[9,12]$ which has been attributed to greater recognition of the adverse effects of oral iron and the "ease" of intravenous iron administration [13]. A recent meta-analysis suggests there may be a decreased need for blood transfusion in women treated with intravenous versus oral iron for IDAP, however the quality of the evidence was rated as low [14] with many studies of poor quality and not measuring important clinical outcomes [15]. Furthermore, intravenous iron has cost implications [12], is infrequently associated with serious adverse effects, including major allergic reactions in 3.6/1000 women [16] and carries a risk of skin staining that has led to a number of notifications to medical defence organisations in Australia [17].

The increased use of intravenous iron in Australia warrants a better understanding of current perinatal prescribing practices. This study therefore aimed to identify the current knowledge, attitudes and behaviours regarding intravenous iron prescription of fellows of the Royal Australian and New Zealand College of Obstetricians and Gynaecologists (RANZCOG) including indications for intravenous iron, frequency of prescribing, perceived advantages and disadvantages, and theoretical acceptability of a randomised trial of intravenous iron for firstline IDAP treatment.

\section{Methods}

An anonymous survey of Fellows of the Royal Australian and New Zealand College of Obstetricians and Gynaecologists (FRANZCOG) was undertaken in September 2018. The online survey (Appendix 1) was emailed by the RANZCOG to all Fellows $(n=2275)$, using the online platform SurveyMonkey ${ }^{\mathrm{ma}}$. A follow-up reminder was sent after 2 weeks and the survey was closed after 6 weeks.

Eligible clinicians were FRANZCOGs currently working in the field of obstetrics or both obstetrics and gynaecology. FRANZCOGs who stated they were only working in gynaecology were directed to survey exit and not included in analysis. Survey completion was taken to indicate consent.

Clinician demographic questions included practice duration, region, setting and births/annum. Questions on intravenous iron prescribing focused on the setting, including respectively: a) IDAP: gestation, circumstances under which intravenous iron was prescribed, advantages and disadvantages; b) ID without anaemia in pregnancy: gestation and indication; c) Postpartum: use of intravenous iron. Thresholds for inclusion in a theoretical future randomised controlled trial (RCT) of first-line intravenous iron in pregnancy in the second or third trimester were also identified.

Statistical analysis was performed using IBM SPSS Statistics 25 (IBM SPSS Statistics 25 for Windows, IBM Corporation, Armonk, NY). Descriptive analysis of demographic characteristics included frequency and percentage tabulation while free text responses were analysed using common theme examination. Association between intravenous iron prescribing in pregnancy and clinician demographics was assessed, including time since obtaining FRANZCOG, practice area, setting and number of births. Similarly, association between clinician subgroups including practice setting and duration of FRANZCOG with IDAP and ID without anaemia treatment approaches, was assessed using either Pearsons' Chi-Squared or Fisher's Exact tests where appropriate.

Ethical approval was granted by the Human Research Ethics Committee of the South Eastern Sydney Local Health District (SESLHD HREC 16/371).

\section{Results}

Overall, 484 fellows responded to the survey (response rate $=21 \%$ ), of whom the majority were obstetricians and gynaecologists $(n=388)$ or obstetricians alone $(n=$ $69)$. The small minority who practiced solely as gynaecologists $(n=27)$ were excluded from all further analyses. Most clinicians practiced in New South Wales (26\%), Victoria (21\%) or Queensland (19\%), with the majority working in metropolitan centres (public $n=239$, private $n=170$ ) (Table 1 ).

\section{Intravenous iron prescribing}

Almost all respondents indicated they prescribe intravenous iron in pregnancy (96\%) and/or postpartum (85\%), with administration predominantly hospital-based (92\%) (Table 2). A third of clinicians prescribed fewer than 10 infusions per annum (31\%), while a quarter 
Table 1 Clinician Demographics

\begin{tabular}{|c|c|c|}
\hline & Frequency (n) & Percentage (\%) \\
\hline \multicolumn{3}{|l|}{ Clinician type $(n=457)$} \\
\hline Obstetricians & 69 & 15.1 \\
\hline Both obstetricians and gynaecologists & 388 & 84.9 \\
\hline \multicolumn{3}{|c|}{ Time since obtaining FRANZCOG or overseas equivalent $(n=444)$} \\
\hline$<5$ years & 104 & 23.4 \\
\hline $5-9$ years & 74 & 16.7 \\
\hline 10-19years & 115 & 25.9 \\
\hline 20 years or more & 148 & 33.3 \\
\hline Prefer not to say & 3 & 0.7 \\
\hline \multicolumn{3}{|l|}{ Area of practice $(n=444)$} \\
\hline New South Wales & 116 & 26.1 \\
\hline Victoria & 91 & 20.5 \\
\hline Queensland & 83 & 18.7 \\
\hline Western Australia & 42 & 9.5 \\
\hline North Island New Zealand & 35 & 7.9 \\
\hline South Australia & 30 & 6.8 \\
\hline South Island New Zealand & 19 & 4.3 \\
\hline Tasmania & 10 & 2.3 \\
\hline Australian Capital Territory & 8 & 1.8 \\
\hline Prefer not to say & 6 & 1.4 \\
\hline Northern Territory & 4 & 0.9 \\
\hline \multicolumn{3}{|l|}{ Practice setting $(n=444)^{a}$} \\
\hline Metropolitan public hospital & 239 & 53.8 \\
\hline Metropolitan private hospital & 170 & 38.3 \\
\hline Non-metropolitan public hospital & 107 & 24.1 \\
\hline Non-metropolitan private hospital & 33 & 7.4 \\
\hline Prefer not to say & 3 & 0.7 \\
\hline Other $^{\mathrm{b}}$ & 3 & 0.7 \\
\hline \multicolumn{3}{|c|}{ Births per annum in largest hospital of practice $(n=444)$} \\
\hline$<1000$ & 73 & 16.4 \\
\hline $1000-2499$ & 119 & 26.8 \\
\hline 2500-3999 & 106 & 23.9 \\
\hline 4000 or more & 146 & 32.9 \\
\hline \multicolumn{3}{|c|}{ Number of women with IDAP treated per annum $(n=419)$} \\
\hline$<10$ & 42 & 10.0 \\
\hline $10-24$ & 108 & 25.8 \\
\hline $25-49$ & 99 & 23.6 \\
\hline$\geq 50$ & 141 & 33.7 \\
\hline Not sure & 29 & 6.9 \\
\hline \multicolumn{3}{|c|}{ Number of women with ID without anaemia treated per annum $(n=413)$} \\
\hline$<10$ & 70 & 16.9 \\
\hline $10-24$ & 91 & 22.0 \\
\hline $25-49$ & 65 & 15.7 \\
\hline$\geq 50$ & 136 & 32.9 \\
\hline Not sure & 51 & 12.3 \\
\hline
\end{tabular}

Abbreviations: FRANZCOG Fellowship of Royal Australian and New Zealand College of Obstetricians and Gynaecologists; IDAP iron-deficiency anaemia in pregnancy; ID, iron deficiency

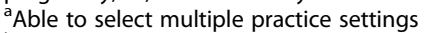

${ }^{b}$ Other practice settings $(n=3)$ included country practice, academia and private practice 
Table 2 Intravenous iron prescribing practices

\begin{tabular}{|c|c|c|}
\hline Question ( $n=$ number of responses) & Frequency (n) & Percentage (\%) \\
\hline \multicolumn{3}{|l|}{ Prescribe IV iron in pregnancy $(n=444)$} \\
\hline Yes & 426 & 95.9 \\
\hline No & 18 & 4.1 \\
\hline \multicolumn{3}{|l|}{ Prescribe IV iron postpartum $(n=429)$} \\
\hline Yes & 364 & 84.8 \\
\hline No & 65 & 15.2 \\
\hline \multicolumn{3}{|c|}{ Location of IV iron administration $(n=421)$} \\
\hline Hospital & 386 & 91.7 \\
\hline Non-hospital & 4 & 1.0 \\
\hline Both & 31 & 7.4 \\
\hline \multicolumn{3}{|c|}{ Number of infusions prescribed in pregnancy and/or postpartum per annum $(n=425)$} \\
\hline$<10$ & 132 & 31.1 \\
\hline $10-19$ & 107 & 25.2 \\
\hline $20-29$ & 80 & 18.8 \\
\hline 30 or more & 97 & 22.8 \\
\hline Don't prescribe & 9 & 2.1 \\
\hline \multicolumn{3}{|l|}{ IV preparation prescribed $(n=425)^{a}$} \\
\hline Ferric carboxymaltose (Ferinject) & 381 & 89.6 \\
\hline Iron polymaltose (Ferrosig, Ferrum-H) & 54 & 12.7 \\
\hline Don't know & 16 & 3.8 \\
\hline Iron sucrose (Venofer) & 11 & 2.6 \\
\hline Other $^{\mathrm{a}}$ & 7 & 1.6 \\
\hline \multicolumn{3}{|c|}{ Gestation range of IV iron prescribing in IDAP $(n=419)^{b}$} \\
\hline Prescribe during pregnancy & 410 & 97.9 \\
\hline$<13$ weeks & 35 & 8.4 \\
\hline 13-27 weeks & 145 & 34.6 \\
\hline$\geq 28$ weeks & 406 & 96.9 \\
\hline Do not prescribe in pregnancy & 9 & 2.1 \\
\hline \multicolumn{3}{|c|}{ Gestation range of IV iron prescribing in pregnancy for ID without anaemia $(n=413)^{7}$} \\
\hline Prescribe during pregnancy & 220 & 53.3 \\
\hline$<13$ weeks & 14 & 3.4 \\
\hline 13-27 weeks & 51 & 12.3 \\
\hline$\geq 28$ weeks & 220 & 53.3 \\
\hline Do not prescribe & 193 & 46.7 \\
\hline
\end{tabular}

Abbreviations: IV intravenous; IDAP iron deficiency anaemia in pregnancy; ID iron deficiency. Superscript: $F$ Fisher's Exact; $C$ Pearson's Chi-Squared ${ }^{a}$ Nil alternative infusions specified

${ }^{b}$ Participants could select multiple ranges

prescribed $10-19(25 \%)$ or 30 or more (23\%) infusions per year. The most commonly prescribed formulation was ferric carboxymaltose (FCM) (90\%). Intravenous iron was mostly prescribed in the third trimester, although a minority prescribed it in the first trimester $(8 \%$ for IDAP, 3\% for ID only).

Overall differences in prescribing practices were small. Those who had obtained their FRANZCOG or overseas equivalent $<10$ years ago were more likely to prescribe intravenous iron $(100 \%$ vs $94 \%$ with FRANZCOG $\geq 10$ years, $P=0.02$ ), as were those practicing in public hospitals ( $97 \%$ vs $91 \%$ for those who were not, $P=0.008$ ) and in hospitals with birth numbers $>2500 /$ annum $(98 \%$ vs 93\% with $<2500 /$ annum, $P=0.01$ ) (Table 3 ).

Perceived advantages of intravenous iron in pregnancy included improvement of iron status parameters in those with poor oral iron tolerance (92\%) and adherence (76\%), late pregnancy IDAP or special circumstances 
Table 3 Intravenous iron prescribing in pregnancy and association with obstetrician demographics

\begin{tabular}{|c|c|c|c|c|}
\hline & \multirow{2}{*}{$\begin{array}{l}\text { Frequency } \\
\text { (n) and } \\
\text { percentage } \\
(\%)\end{array}$} & \multicolumn{2}{|c|}{ IV iron prescribing in pregnancy $(n, \%)^{a}$} & \multirow[t]{2}{*}{$P$-value } \\
\hline & & Yes & No & \\
\hline \multicolumn{5}{|c|}{ Time since obtaining FRANZCOG or overseas equivalent $(n=441)$} \\
\hline$<10$ years & $178(40.4)$ & $176(98.9)$ & $2(1.1)$ & \multirow[t]{2}{*}{$0.014^{\mathrm{C} *}$} \\
\hline$\geq 10$ years & $263(59.6)$ & $248(94.3)$ & $15(5.7)$ & \\
\hline \multicolumn{5}{|c|}{ Area of practice $(n=438)$} \\
\hline Australia & $384(87.7)$ & $368(95.8)$ & $16(4.2)$ & \multirow[t]{2}{*}{$0.707^{F}$} \\
\hline New Zealand & $54(12.3)$ & $53(98.1)$ & $1(1.9)$ & \\
\hline \multicolumn{5}{|c|}{ Practice setting $(n=441)$} \\
\hline Metropolitan ${ }^{\mathrm{b}}$ & $323(73.2)$ & $310(96.0)$ & $13(4.0)$ & \multirow[t]{2}{*}{$1.000^{F}$} \\
\hline Non-metropolitan & $118(26.8)$ & $113(95.8)$ & $5(4.2)$ & \\
\hline Public ${ }^{c}$ & $342(77.6)$ & $333(97.4)$ & $9(2.6)$ & \multirow[t]{2}{*}{$0.008^{F_{* * *}}$} \\
\hline Not public & $99(22.4)$ & $90(90.9)$ & $9(9.1)$ & \\
\hline \multicolumn{5}{|c|}{ Births per annum in largest hospital of practice $(n=444)$} \\
\hline$<2500$ & $192(43.2)$ & $179(93.2)$ & $13(6.8)$ & \multirow[t]{2}{*}{$0.011^{C * * *}$} \\
\hline$>2500$ & $252(56.8)$ & $247(98.0)$ & $5(2.0)$ & \\
\hline
\end{tabular}

Abbreviations: IV intravenous; FRANZCOG Fellowship of Royal Australian and New Zealand College of Obstetricians and Gynaecologists. Superscript: F, Fisher's Exact; $C$, Pearson's Chi-Squared

${ }^{\mathrm{a}} n=444$

b"Metropolitan" represents clinicians whose practice sites include metropolitan public and/or metropolitan private hospitals; "non-metropolitan" includes clinicians who practice exclusively in non-metropolitan public hospitals, non-metropolitan private hospitals or others

"Public" represents clinicians whose practice sites include metropolitan public and/or non-metropolitan public hospitals; "not public" includes clinicians who practice exclusively in metropolitan private hospitals, non-metropolitan private hospitals or others

(76\%), and its rapid improvement of iron status parameters $(60 \%)$. Among 'other' advantages specified were specific difficulties of oral iron use $(n=6)$, the avoidance of blood transfusion $(n=4)$, improvement of iron stores following postpartum haemorrhage $(\mathrm{PPH})(n=3)$, reduced PPH risk $(n=1)$ and maternal QOL outcomes $(\mathrm{n}=1)$ (Table 4).

Disadvantages identified by clinicians included maternal adverse outcomes (58\%), requirement for venepuncture (57\%), practical difficulties of administration (44\%) and high cost to the health service (31\%). 'Other' commonly identified disadvantages included the risk of anaphylaxis $(n=18)$, risk of allergic reactions $(n=10)$ and other adverse effects $(n=$ 12) (Table 4).

The principal treatment approach for IDAP was 'oral iron usually first-line therapy, intravenous iron may be used as first-line therapy in special circumstances, and intravenous iron always used as second-line therapy if first-line oral iron fails' (59\%). For ID without anaemia, the predominant treatment approach stated by respondents was 'oral iron always as first-line therapy, intravenous iron may be used as second-line therapy in certain circumstances (e.g. patient intolerant of oral iron and still iron deficient late in pregnancy)' (46\%) (Fig. 1). There were no differences in approach to the treatment of IDAP or ID without anaemia in pregnancy by clinicians in private practice compared to public practice (Table 5).

Reasons for prescribing intravenous iron for ID without anaemia in pregnancy included intolerance of oral iron (44\%), women identifying as Jehovah's witness (32\%), high bleeding risk (31\%) and convenience (5\%). Common theme analysis of 'other' reasons $(n=29)$, indicated importance of symptoms including extreme maternal fatigue (Table 4). Forty-three percent of clinicians $(n=178)$ stated they do not prescribe intravenous iron in this context.

Common indications for the use of intravenous iron postpartum included presence of symptoms (68\%), oral iron intolerance (51\%), special circumstances such as Jehovah's witness $(50 \%)$, and likely oral iron nonadherence post-discharge (43\%). Where clinicians indicated that they only prescribe intravenous iron postpartum below a certain haemoglobin threshold (58\%), of those that specified levels these included $<70 \mathrm{~g} / \mathrm{L}(n=5),<80 \mathrm{~g} / \mathrm{L}(n=$ $16),<90 \mathrm{~g} / \mathrm{L}(n=26)$ with one clinician additionally specifying acute bleed, $<100 \mathrm{~g} / \mathrm{L}(n=21)$ with additional specifiers including postpartum haemorrhage and other symptoms, < $110 \mathrm{~g} / \mathrm{L}(\mathrm{n}=1)$ and $<115 \mathrm{~g} / \mathrm{L}(\mathrm{n}=1)$.

\section{Thresholds for theoretical trial inclusion}

Most clinicians (90\%) would consider a theoretical randomised trial as an option. Inclusion thresholds for a 
Table 4 Free text responses

\section{Common themes}

\section{Advantages of IV iron}

Specific difficulties with oral iron $(n=6)$

Avoidance of blood transfusion $(n=4)$

Reduced PPH risk $(\mathrm{n}=1)$

Maternal QOL outcomes $(n=1)$

Others $(n=8)$

\section{Disadvantages of IV iron}

Anaphylaxis $(n=18)$

Other adverse effects $(n=12)$

Risk of allergic reactions $(n=10)$

Administrative difficulties $(n=4)$

Cost and resource factors $(n=4)$

Over-prescription $(n=3)$

Lack of evidence regarding improved pregnancy outcomes $(n=2)$

Others $(n=7)$

\section{Indications for IV iron in the treatment of iron deficiency without anaemia}

Symptomatic iron deficiency $(n=9)$

Special circumstances $(n=4)$

Not used $(n=4)$

Women's preference $(n=3)$

Response to oral iron $(n=3)$

Precaution in case of PPH $(n=2)$

Other $(n=4)$

\section{Representative responses}

Avoid side effects of oral iron

Noncompliance with oral iron

Women bleed less at delivery

Symptomatic women

Severe iron deficiency

Potential side effects

Adverse reactions in up to $20 \%$

Possibility of allergic reactions

It's often not necessary

Lack of evidence on its efficacy was not well tolerated. constipation, nausea

Patient request Lack of response to oral iron
Low ferritin, not responding to oral iron

Avoids the daily hassle of taking oral tabs

Reduction in need for transfusion peri-partum

Well timed, it can be a step to consider before packed RBCs transfusion, although this consideration has more merit in the immediate postpartum period

Useful after a mild postpartum haemorrhage

Postpartum haemorrhage when $\mathrm{Hb}$ is between 7 and 9

Health related QOL outcomes https:/Www.ncbi.n/m.nih.gov/pmc/articles/PMC3488743/

Although NOT in favour of infusion, hospital dictates one to implement infusion

You know the iron status will improve

Risk of anaphylaxis (although low)

Anaphylaxis $1 / 1000=$ risk to mother and baby

Risk of allergic and anaphylactoid events not inconsiderable and overall adverse reactions - a few/100

Tedious process to prescribe. Too much admin for clinic

Cost of (hospital) admission to administer the drug

Cost to health services and personal needed

Over prescribed, e.g. women with low serum iron but normal $\mathrm{Hb}$

No evidence of improved outcome of pregnancy; possible increased adverse outcome

Minimal disadvantages - a few have reactions, mainly fever but not seen major adverse effects

Most women prefer it compared to side effects of oral iron

Risks of toxicity, huge doses used are above physiological, risks of free radical generation

Extreme tiredness after other options tried

Very rarely if restless legs or severe fatigue if not tolerating oral supplementation

Hyperemesis with PICC (peripherally inserted central) line, influenza or bronchitis, bowel disease I would only do this where a woman was unable to access regular antenatal care ... and where oral iron

Intolerance to oral iron in a Jehovah's witness with a high bleeding risk

I have recently modified my practice so that the target is $\mathrm{Hb}$ not ferritin. I therefore ... modify oral iron supplements ... and actively try to avoid IV infusions of iron

In my institution I do not prescribe, but many others do

Women prefer it. Most of the women I see dislike oral replacement and avoid secondary to sides effects, i.e.

Failure of oral iron supplements with falling Hb AND altered RBC indices

To increase iron store as a precaution against PPH

Only on the advice of obstetric medicine colleagues Iron deficiency (with or without anaemia) is a condition that requires treatment. Aim for normal iron stores in fetus

Would consider on case by case. Wouldn't routinely measure iron unless anaemic or if notable drop over successive trimesters. 
theoretical RCT of first-line oral iron versus intravenous iron in pregnancy in order of acceptability were IDAP with $\mathrm{Hb}<100 \mathrm{~g} / \mathrm{L}(54 \%)$, IDAP with any $\mathrm{Hb}$ threshold in the presence of special circumstances (47\%), followed by IDAP with $\mathrm{Hb}<90 \mathrm{~g} / \mathrm{L}$ (36\%) and ID with Ferritin < $15 \mu \mathrm{g} / \mathrm{L}$ (35\%) (Table 6). Identifying IDAP with any level $\mathrm{Hb}$ as an appropriate threshold for inclusion was associated with public practice setting $(P=0.04)$, while perceiving that the trial was not an option was associated with longer FRANZCOG duration $(P=0.009)$.

\section{Discussion}

This survey is the best available representation of current practice towards treatment of ID in pregnancy by specialist obstetricians in Australia and New Zealand. Given that over three quarters of obstetricians surveyed work in public hospitals, these findings may be extrapolated to public hospitals. There are high rates of intravenous iron use by obstetricians in Australia and New Zealand for ID and IDAP, predominantly in hospital settings and most commonly in later gestation. While around half of obstetricians prescribe $<20$ infusions per annum, almost a quarter prescribe 30 or more infusions a year. Interestingly, $8 \%$ of clinicians stated they prescribed intravenous iron in the first trimester for either IDAP and/or ID without anaemia, despite this being contraindicated [18].

The key point highlighted by our findings is that the prescribing of FRANZCOGs for the treatment of ID in pregnancy is not consistent with Australian antenatal care guidelines or patient blood management guidelines $[1,10,11]$ There is an appropriate differentiation between IDAP and ID without anaemia in pregnancy, acknowledging the evidence of increased risk of adverse maternal and fetal outcomes with maternal anaemia [4, $5,7]$. Nonetheless, intravenous iron is commonly prescribed for women with ID without anaemia, a shift in practice that has been well recognised recently. This survey highlights that some instances of use in this cohort are established indications, for example women identifying as Jehovah's witness or of high bleeding risk [10], however convenience $(5 \%)$, poor tolerance of oral iron and severity of maternal symptoms as indications for use represent a clear departure between recommendations and practice [11]. This may be interpreted as failure to capture this shift in clinicians views' or alternately that this reiterates the lack of quality clinical outcomes data, resulting in heterogenous practice. Irrespective, increasingly liberal use of intravenous iron may overlook the potential risk of serious, albeit uncommon side effects such as anaphylaxis and permanent skin tattooing [14], particularly in settings with less rigorous benefit data. Additionally, it must be noted that the fetal safety of intravenous iron remains unclear. It has been postulated that delivering large iron loads over a short time period in intravenous infusions, may increase the risk of iron free radicals inducing oxidative damage to vulnerable placental tissues $[19,20]$.

Intravenous iron unequivocally improves haematological parameters, with a recent meta-analysis finding a mean difference in maternal haemoglobin of $0.85 \mathrm{~g} / \mathrm{L}$ and ferritin of $63.3 \mu \mathrm{g} / \mathrm{L}$ [14]. However, clinical outcome data such as quality of life (QOL), breast feeding rates, preterm birth and postnatal depression was not well

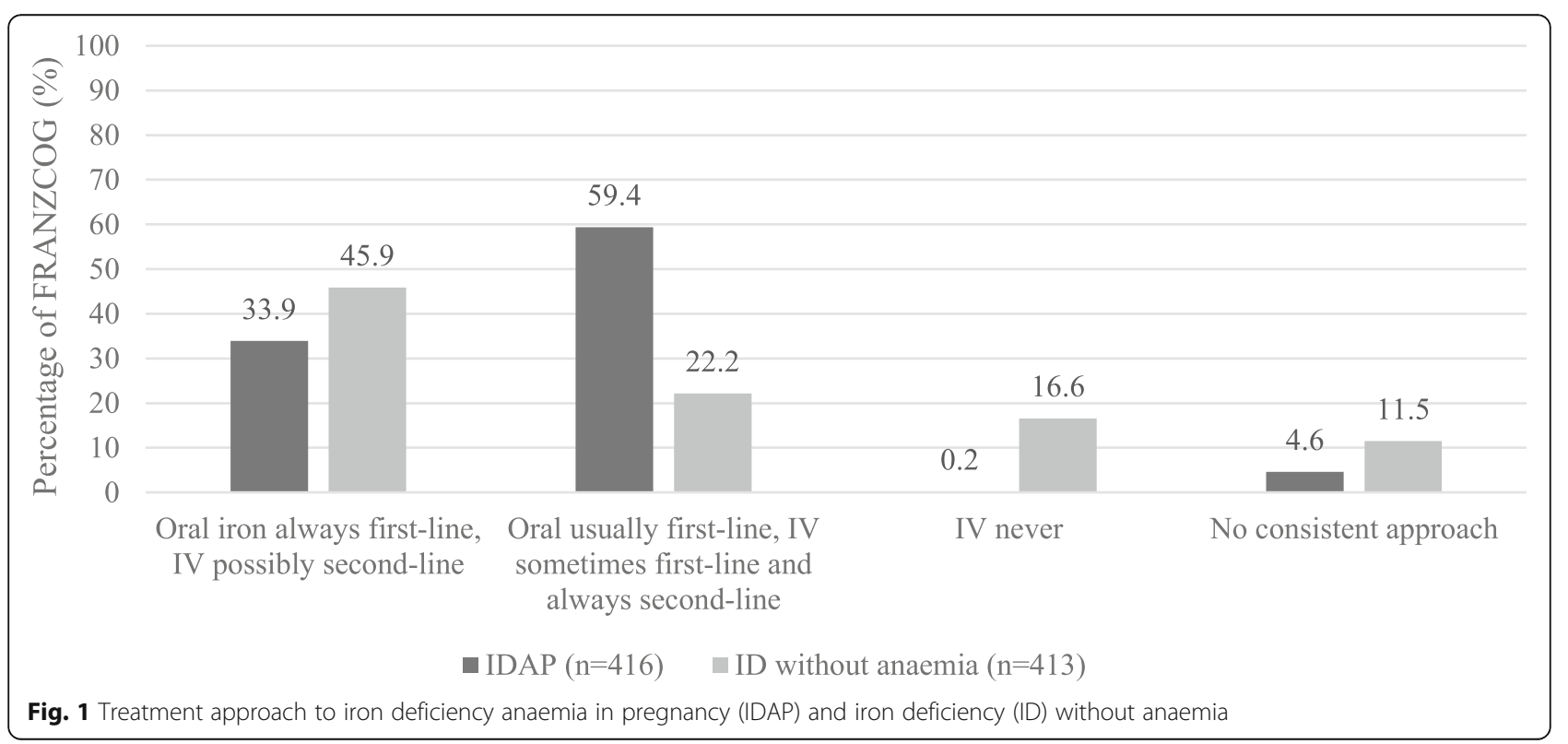


Table 5 Treatment approach in pregnancy and association with practice setting

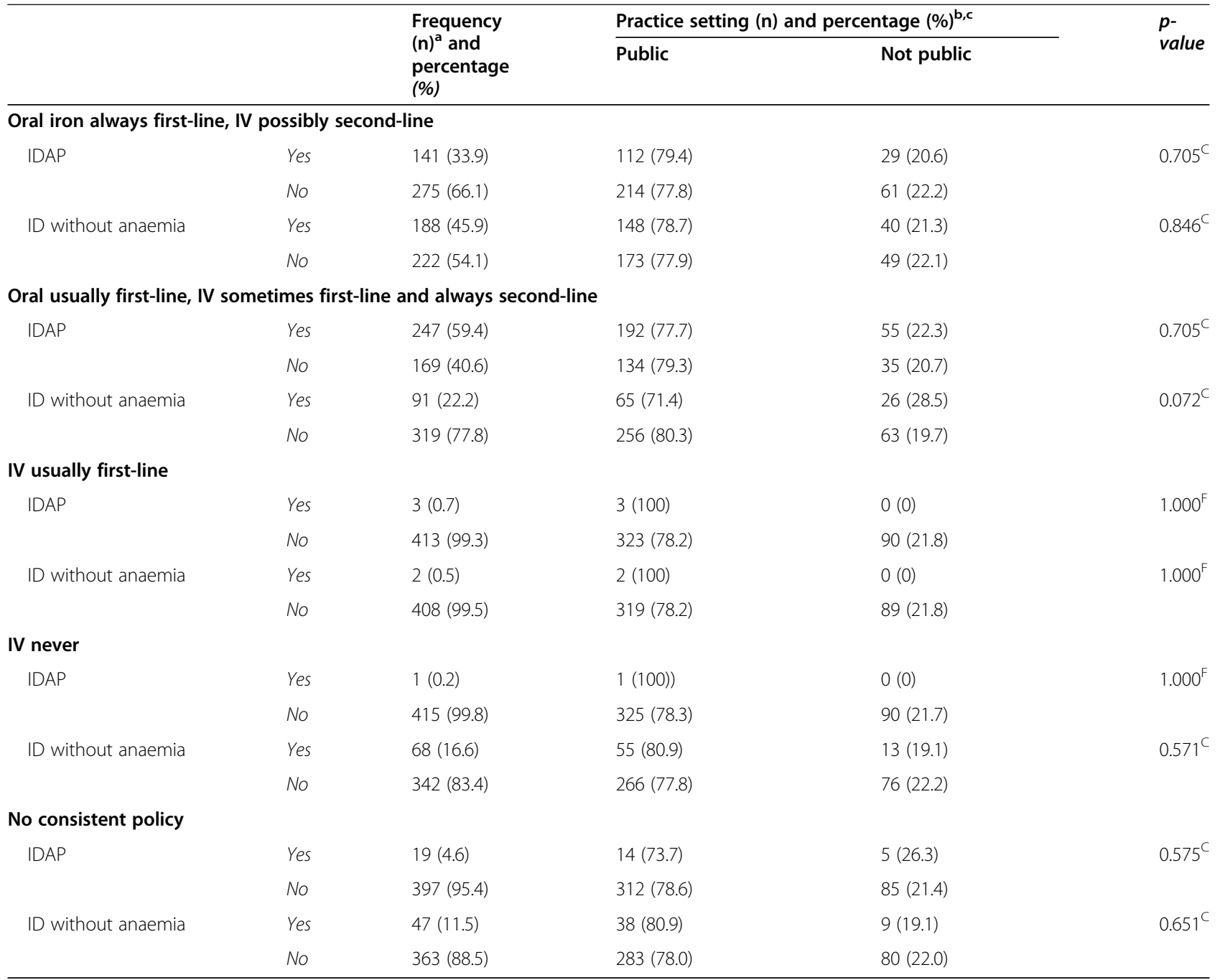

Abbreviations: IV intravenous; IDAP iron deficiency anaemia in pregnancy; ID iron deficiency. Superscript: F, Fisher's Exact; C, Pearson's Chi-Squared

${ }^{\mathrm{a}}$ For IDAP $n=416$; For ID without anaemia $n=413$

${ }^{\mathrm{b}}$ For practice setting analysis IDAP $\mathrm{n}=416$, ID without anaemia $n=410$

"Public" represents clinicians whose practice sites include metropolitan public and/or non-metropolitan public hospitals; "not public" includes clinicians who practice exclusively in metropolitan private hospitals, non-metropolitan private hospitals or others

reported in the studies included in this meta-analysis, many of which were undertaken in low and middle income countries. The 2011 Cochrane review identified the need for assessment of clinical outcomes and effects of treatments of IDAP in large, quality randomised trials [8]. Secondary endpoints of a recent Australian RCT for IDAP comparing intravenous FCM, intravenous polymaltose (IPM) and oral iron sulphate (IS) found that higher overall serum ferritin was associated with an improvement in QOL [21]. Findings of this study are difficult to interpret given the association between QOL improvement and intravenous iron was indirect; QOL was improved with higher overall serum ferritin, which was achieved in groups of women receiving intravenous iron. Similarly, an international multi-centre RCT comparing first-line FCM and oral IS demonstrated that improved pre-delivery vitality scores and social functioning were significantly associated with FCM [22]. Both studies are biased by their open-label nature, a major limitation given QOL measures are self-reported. Additionally, the latter study was sponsored by a pharmaceutical company. Without substantial evidence of clinical superiority of intravenous iron, its use in firstline treatment of IDAP and ID highlights the importance of addressing non-evidence based treatment trends before they become common practice [9].

FCM was the most commonly used intravenous preparation, consistent with its favourable safety profile with moderate or severe ADRs occurring in the realm of 3.6/ 1000 for FCM versus 14.0/1000 for IPM and 7.9/1000 for IS [16]. FCM also has a shorter infusion time than IPM so may have lower administration (nursing) costs 
Table 6 Inclusion thresholds for theoretical trial and association with practice setting and FRANZCOG Duration

\begin{tabular}{|c|c|c|c|c|c|c|c|c|}
\hline \multicolumn{2}{|l|}{ Thresholds deemed appropriate } & \multirow{2}{*}{$\begin{array}{l}\text { Frequency } \\
(\mathrm{n})^{\mathrm{a}} \text { and } \\
\text { percentage } \\
(\%)\end{array}$} & \multicolumn{2}{|c|}{$\begin{array}{l}\text { Practice setting }(n)^{a} \text { and } \\
\text { percentage }(\%)\end{array}$} & \multirow[t]{2}{*}{$\begin{array}{l}p- \\
\text { value }\end{array}$} & \multicolumn{2}{|c|}{$\begin{array}{l}\text { Time since obtaining FRANZCOG (n) } \\
\text { and percentage }(\%)\end{array}$} & \multirow[t]{2}{*}{$p$-value } \\
\hline & & & Public & Not public & & $<10$ years & $>10$ years & \\
\hline \multicolumn{9}{|l|}{ IDAP } \\
\hline \multirow[t]{2}{*}{ Any $\mathrm{Hb}$} & Yes & $114(26.6)$ & $79(69.9)$ & $34(30.1)$ & $0.038^{\mathrm{C} *}$ & $50(43.9)$ & $64(56.1)$ & $0.243^{C}$ \\
\hline & No & $314(73.4)$ & $248(79.5)$ & $64(20.5)$ & & $117(37.6)$ & $194(62.4)$ & \\
\hline \multirow[t]{2}{*}{$\mathrm{Hb}<100 \mathrm{~g} / \mathrm{L}$} & Yes & $232(54.2)$ & $177(77.0)$ & $53(23.0)$ & $0.993^{C}$ & $97(42.0)$ & $134(58.0)$ & $0.214^{C}$ \\
\hline & No & $196(45.8)$ & $150(76.9)$ & $45(23.1)$ & & $70(36.1)$ & $124(63.9)$ & \\
\hline \multirow[t]{2}{*}{$\mathrm{Hb}<90 \mathrm{~g} / \mathrm{L}$} & Yes & $155(36.2)$ & $116(75.8)$ & $37(24.2)$ & $0.680^{C}$ & $57(36.8)$ & $98(63.2)$ & $0.420^{C}$ \\
\hline & No & $273(63.8)$ & $211(77.6)$ & $61(22.2)$ & & $110(40.7)$ & $160(59.3)$ & \\
\hline \multirow[t]{2}{*}{$\mathrm{Hb}<80 \mathrm{~g} / \mathrm{L}$} & Yes & $140(32.7)$ & $105(76.1)$ & $33(23.9)$ & $0.772^{C}$ & $51(36.3)$ & $89(63.6)$ & $0.397^{C}$ \\
\hline & No & $288(67.3)$ & $222(77.4)$ & $65(22.6)$ & & $116(40.7)$ & $169(59.3)$ & \\
\hline \multirow[t]{2}{*}{ Any $\mathrm{Hb}$ in special circumstances ${ }^{\mathrm{b}}$} & Yes & $202(47.2)$ & $158(78.6)$ & $43(21.4)$ & $0.440^{c}$ & $78(38.3)$ & $123(61.2)$ & $0.845^{C}$ \\
\hline & No & $226(52.8)$ & $169(75.4)$ & $55(24.6)$ & & $89(39.7)$ & $135(60.3)$ & \\
\hline \multicolumn{9}{|l|}{ ID without anaemia } \\
\hline \multirow[t]{2}{*}{ Ferritin $<30 \mu \mathrm{g} / \mathrm{L}$} & Yes & $42(9.8)$ & $29(69.0)$ & $13(31.0)$ & $0.201^{c}$ & $20(47.6)$ & $22(52.4)$ & $0.245^{C}$ \\
\hline & No & $386(90.2)$ & $298(77.8)$ & $85(22.2)$ & & $147(38.4)$ & $236(61.6)$ & \\
\hline \multirow[t]{2}{*}{ Ferritin $<15 \mu \mathrm{g} / \mathrm{L}$} & Yes & $151(35.3)$ & $116(76.8)$ & $35(23.2)$ & $0.965^{C}$ & $55(36.7)$ & $95(63.3)$ & $0.413^{C}$ \\
\hline & No & $277(64.7)$ & $211(77.0)$ & $63(23.0)$ & & $112(40.7)$ & $163(59.3)$ & \\
\hline \multirow[t]{2}{*}{ Trial not an option } & Yes & $45(10.5)$ & $34(77.3)$ & $10(22.7)$ & $0.956^{C}$ & $9(20.9)$ & $34(79.1)$ & $0.009^{C * *}$ \\
\hline & No & $383(89.5)$ & $293(76.9)$ & $88(23.1)$ & & $158(41.4)$ & $224(58.6)$ & \\
\hline \multirow[t]{2}{*}{ Other } & Yes & $20(4.7)$ & $16(80.0)$ & $4(20.0)$ & $1.000^{F}$ & $5(25.0)$ & $15(75.0)$ & $0.180^{C}$ \\
\hline & No & $408(95.3)$ & $311(76.8)$ & $94(23.2)$ & & $162(40.0)$ & $243(60.0)$ & \\
\hline
\end{tabular}

Abbreviations: FRANZCOG Fellowship of Royal Australian and New Zealand College of Obstetricians and Gynaecologists; IDAP iron deficiency anaemia in pregnancy; ID iron deficiency; $\mathrm{Hb}$ haemoglobin. Superscript: F, Fisher's Exact; $C$, Pearson's Chi-Squared

a"Public" represents clinicians whose practice sites include metropolitan public and/or non-metropolitan public hospitals; "not public" includes clinicians who practice exclusively in metropolitan private hospitals, non-metropolitan private hospitals or others

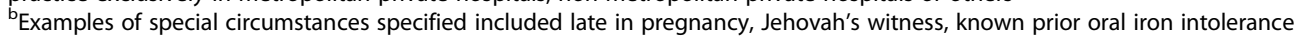

for outpatients, despite the preparation itself being more costly [14, 21]. FCM was listed on the Australian Pharmaceutical Benefits Scheme in 2014 and the New Zealand Pharmaceutical Management Agency in 2017, the former to which Seeho et al., (2018) largely attributes the rise in intravenous iron use [9]. Our findings also support the significant healthcare burden of ID with or without anaemia in pregnancy, with roughly one third of respondents treating at least fifty women per annum with IDAP (34\%) and ID without anaemia (33\%).

Oral iron intolerance was stated as a reason for intravenous iron prescription by some obstetricians. Although oral iron treatment strategies were not addressed in this survey, it is important to highlight the recently recognised role of 'risk mitigation' strategies used to improve tolerance and compliance, including reduced dose elemental iron, intermittent dosing, and avoidance of twice daily dosing [13]. The recently published British Society of Haematology guidelines outline the strategies that can be used to reduce symptoms of oral iron and lead to improve compliance and hence correction of iron deficiency anaemia [20].

The findings from our study support the acceptance of a potential RCT for firstline use of intravenous iron in pregnancy for IDAP (not ID alone) with a haemoglobin cut off of $100 \mathrm{~g} / \mathrm{L}$, where most clinicians would consider including their patients. While the lack of universal cutoffs for haematological measures of iron status in pregnancy is recognised as a research need [23], lowering inclusion thresholds could meaningfully reduce a potential IDAP study cohort in an Australian and New Zealand setting, where severe IDAP is uncommon. Indeed, Khalafallah et al's recent Australian RCT used a haemoglobin threshold extending to $\leq 120 \mathrm{~g} / \mathrm{L}$, well above IDAP thresholds defined by Australian guidelines and those deemed acceptable by our cohort [21]. As such, understanding factors impacting a potential trial of first-line intravenous versus oral iron for IDAP is critical to ensuring a future study utilises appropriate and feasible inclusion thresholds and measures clinical outcomes that will meaningfully inform practice. 


\section{Limitations of this study}

Strengths of this study include that it reflects current practice by specialist obstetricians in Australia and New Zealand in both urban and metropolitan areas. Our study was limited by the low response rate, however this was comparable to similar studies of the RANZCOG membership of $19-23 \%$, and still represents a sizeable cohort $[24,25]$. Nonetheless, potential self-selection bias must be acknowledged as a limitation, particularly in light of this response rate; as with any survey, those that have greater interest or more strongly held views on a topic may be more inclined to complete the survey. Another perceived limitation may be that this survey failed to capture the views of other health care professionals involved in antenatal care, particularly general practitioners who are responsible for up to $50 \%$ of intravenous iron prescribing for women of reproductive age [12]. However, although Australian national prescribing data does not provide a breakdown on intravenous iron prescribing in pregnancy versus non-pregnant reproductiveage women, our observational experience is that general practitioners are reluctant to administer intravenous iron in pregnancy outside the hospital setting, and so likely represent a small proportion of intravenous iron prescribers in pregnancy. Obstetric physicians in tertiary centres are another important prescribing group not captured by this survey, although this speciality group has few practicing members in Australia. That being said, the rationale for restricting the survey population to FRANZCOGs alone was to establish the consensus among obstetricians regarding ID treatment, as those most likely to influence local policy and to be involved in a potential trial.

\section{Conclusions}

Many obstetricians in Australia and New Zealand prescribe intravenous iron for IDAP, while half prescribe it for ID without anaemia. Adherence to national guidelines regarding use of intravenous iron appeared suboptimal. Further research is required into the optimal treatment of IDAP and ID without anaemia in antenatal and postnatal settings, particularly establishing important clinical outcomes. It is therefore encouraging that a prospective RCT was acceptable to most clinicians.

\section{Supplementary Information}

The online version contains supplementary material available at https://doi. org/10.1186/s12884-020-03363-3.

\section{Additional file 1.}

\section{Abbreviations}

IDAP: Iron deficiency anaemia in pregnancy; ID: Iron deficiency; RANZCOG: Royal Australian and New Zealand College of Obstetricians and Gynaecologists; FRANZCOG: Fellowship of the Royal Australian and New
Zealand College of Obstetricians and Gynaecologists; RCT: Randomised controlled trial; FCM: Ferric carboxymaltose; PPH: Postpartum haemorrhage; QOL: Quality of life; IPM: Iron polymaltose; IS: Iron sulphate

\section{Acknowledgements}

The authors would like to acknowledge the contribution of the RANZCOG Continued Professional Development committee in circulating the online survey link. Participants could claim one Continued Professional Development point for survey completion, as per standard RANZCOG practice.

\section{Authors' contributions}

SSW contributed to survey design, data analysis and drafted the work. $\mathrm{AH}$, AS and GKG contributed to survey design, data interpretation and work revising. LG contributed to data interpretation and work revising. The author(s) read and approved the final manuscript.

\section{Funding}

$\mathrm{AH}$ receives salary support in the form of an Australian National Health and Medical Research Council (NHMRC) Early Career Fellowship (RG1141570) and this support is gratefully acknowledged. The Fellowship is not related to this research project or its topic area. The authors declare that they have no conflicting interests.

\section{Availability of data and materials}

The datasets generated and analysed during the current study are included in this published article [RANZCOG Data Spreadsheet].

\section{Ethics approval and consent to participate}

Ethical approval was given by the Human Research Ethics Committee of the South Eastern Sydney Local Health District (SESLHD HREC 16/371).

Completion of survey was taken to indicate consent.

\section{Consent for publication}

Not applicable.

\section{Competing interests}

The authors declare that they have no competing interests.

\section{Author details}

${ }^{1}$ School of Women's and Children's Health, University of New South Wales, Kensington, NSW, Australia. ${ }^{2}$ Haematology Department, Prince of Wales Hospital, Randwick, NSW, Australia. ${ }^{3}$ Children's Hospital at Westmead Clinical School, The University of Sydney, Sydney, NSW, Australia. ${ }^{4}$ The Royal Hospital for Women, Randwick, NSW, Australia. ${ }^{5}$ Adelaide Medical School, Robinson Research Institute, University of Adelaide, Adelaide, SA, Australia. ${ }^{6}$ SA Pharmacy, Flinders Medical Centre, SA Health, Bedford Park, Adelaide, SA, Australia. 7 Department of Women's and Children's Health, Level 2, Prichard Wing, St George Hospital, Sydney, NSW, Australia. ${ }^{8}$ The George Institute for Global Health, Sydney, NSW, Australia.

Received: 22 July 2020 Accepted: 27 October 2020

Published online: 04 November 2020

\section{References}

1. World Health Organization. Guideline: Daily iron and folic acid supplementation in pregnant women. Geneva; World Health Organization; 2012.

2. Khalafallah A, Dennis A, Bates J, et al. A prospective randomized, controlled trial of intravenous versus oral iron for moderate iron deficiency anaemia of pregnancy. J Intern Med. 2010;268:286-95.

3. Zhou SJ, Gibson RA, Crowther CA, Baghurst P, Makrides M. Effect of iron supplementation during pregnancy on the intelligence quotient and behavior of children at $4 \mathrm{y}$ of age: long-term follow-up of a randomized controlled trial. Am J Clin Nutr. 2006;83:1112-7.

4. Bencaiova G, von Mandach U, Zimmermann R. Iron prophylaxis in pregnancy: intravenous route versus oral route. Eur J Obstet Gynecol Reprod Biol. 2009;144:135-9.

5. Daru J, Zamora J, Fernández-Félix BM, et al. Risk of maternal mortality in women with severe anaemia during pregnancy and post partum: a multilevel analysis. Lancet Glob Health. 2018;6:e548-e54. 
6. Nair M, Churchill D, Robinson S, Nelson-Piercy C, Stanworth SJ, Knight M. Association between maternal haemoglobin and stillbirth: a cohort study among a multi-ethnic population in England. Br J Haematol. 2017;179:82937.

7. Parker JA, Barroso F, Stanworth SJ, et al. Gaps in the evidence for prevention and treatment of maternal anaemia: a review of systematic reviews. BMC Pregnancy Childbirth. 2012;12:56.

8. Reveiz L, Gyte G, Cuervo L, Casabuenas A. Treatments for iron-deficiency anaemia in pregnancy. Cochrane Database Syst Rev. 2011;10:CD003094.

9. Seeho S, Morris J. Intravenous iron use in pregnancy: ironing out the issues and evidence. Aust N Z J Obstet Gynaecol. 2018:58:145-7.

10. National Blood Authority. Patient Blood Management Guidelines: Module 5 - Obstetrics and Maternity: (2015).

11. Department of Health. Clinical practice guidelines: pregnancy care. Canberra: Australian Government Department of Health; 2019.

12. Shand A, Bell J, Henry A, et al. Rapid increase in intravenous iron use among women of reproductive age in Australia: a population based study In press.

13. DeLoughery TG. Safety of Oral and intravenous Iron. Acta Haematol. 2019; 142:8-12.

14. Qassim A, Grivell RM, Henry A, Kidson-Gerber G, Shand A, Grzeskowiak LE. Intravenous or oral iron for treating iron deficiency anaemia during pregnancy: systematic review and meta-analysis. Med J Aust. 2019;211:36773.

15. Malinowski AK, D'Souza R, Khan KS, Shehata N, Malinowski M, Daru J. Reported outcomes in perinatal Iron deficiency Anemia trials: a systematic review. Gynecol Obstet Investig. 2019:1-18.

16. Qassim A, Mol B, Grivell R, Grzeskowiak L. Safety and efficacy of intravenous iron polymaltose, iron sucrose and ferric carboxymaltose in pregnancy: a systematic review. Aust N Z J Obstet Gynaecol. 2018;58:22-39.

17. Canning $\mathrm{M}$, Gilmore K. Iron stain following an intravenous iron infusion. Med J Aust. 2017;207:58.

18. Joint United Kingdom Blood Transfusion and Tissue Transplantation Services Professional Advisory Committee. Alternatives and adjuncts to blood transfusion: Parenteral iron. Handbook of Transfusion Medicine. 5th ed; 2014

19. Boughton S, Chen L, Kidson-Gerber G, Curtain C, Zaidi STR, Henry A. Intravenous iron sucrose and ferric carboxymaltose in pregnant patients: an observational study of maternal efficacy and tolerance. J Pharm Pract Res. 2017:47:419-25

20. Pavord S, Daru J, Prasannan N, Robinson S, Stanworth S, Girling J. UK guidelines on the management of iron deficiency in pregnancy. $\mathrm{Br} J$ Haematol. 2019;156:588-600.

21. Khalafallah A, Hyppa A, Chuang A, et al. A prospective randomised controlled trial of a single intravenous infusion of ferric carboxymaltose, versus single intravenous iron polymaltose or daily oral ferrous sulphate in the treatment of iron deficiency anaemia in pregnancy. Semin Hematol. 2018:156(5):588-600

22. Breymann C, Milman N, Mezzacasa A, Bernard R, Dudenhausen J. Ferric carboxymaltose vs. oral iron in the treatment of pregnant women with iron deficiency anemia: an international, open-label, randomized controlled trial (FER-ASAP). J Perinat Med. 2017;45:443-53.

23. Pena-Rosas JP, De-Regil LM. Garcia-Casal MN and Dowswell T. Daily oral iron supplementation during pregnancy. Cochrane Database Syst Rev. 2015;7: CD004736.

24. Seeho SKM, Nippita TA, Roberts CL, Morris JM, Nassar N. Venous thromboembolism prophylaxis during and following caesarean section: a survey of clinical practice. Aust N Z J Obstet Gynaecol. 2016;56:54-9.

25. Shand AW, Harpham ME, Lainchbury A, McCormack L, Leung S, Nassar N. Knowledge, advice and attitudes toward women driving a car after caesarean section or hysterectomy: a survey of obstetrician/gynaecologists and midwives. Aust N Z J Obstet Gynaecol. 2016;56:460-5.

\section{Publisher's Note}

Springer Nature remains neutral with regard to jurisdictional claims in published maps and institutional affiliations.

\section{Ready to submit your research? Choose BMC and benefit from:}

- fast, convenient online submission

- thorough peer review by experienced researchers in your field

- rapid publication on acceptance

- support for research data, including large and complex data types

- gold Open Access which fosters wider collaboration and increased citations

- maximum visibility for your research: over $100 \mathrm{M}$ website views per year

At BMC, research is always in progress.

Learn more biomedcentral.com/submissions 